\title{
Designing a Social Learning Analytics Tool for Open Annotation and Collaborative Learning
}

Preprint of book chapter accepted for publication in P. Prinsloo, S. Slade, \& M. Khalil (Eds.), Learning analytics in open and distributed learning: Potentials and challenges.

Please cite as:

Kalir, J. (in press). Designing a social learning analytics tool for open annotation and collaborative learning. In P. Prinsloo, S. Slade, \& M. Khalil (Eds.), Learning analytics in open and distributed learning: Potentials and challenges. SpringerOpen.

Correspondence concerning this preprint should be addressed to:

Jeremiah H. Kalir

University of Colorado Denver

School of Education and Human Development

1380 Lawrence St., Suite 645

Denver, CO 80204

(303) 315-0034

remi.kalir@ucdenver.edu 


\title{
Designing a Social Learning Analytics Tool for Open Annotation and Collaborative Learning
}

\author{
Jeremiah H. Kalir \\ University of Colorado Denver
}

"Writing on writing is both literally and metaphorically an important part of the way meaning is negotiated." - Brown and Duguid, 1996

\section{Introduction}

Imagine this book annotated. Picture probable marginalia, marks of readers' attention, perhaps even the stain of a coffee cup. This chapter examines why the social and technical practice of annotation-and, specifically, annotation that accompanies digital and openly accessible texts-is relevant to the development of learning analytics in open, flexible, and distance learning (OFDL; Zhang, Burgos, \& Dawson, 2019).

The probable social future of this book, as an academic text written for specialists and novices, includes its likely annotation in coursework, by research teams, and because the coupling of annotation and citation propels forward the production of scholarship (Fajkovic \& Björneborn, 2014; Marshall, 1997). Annotation is the addition of a note to a text. Whether written by hand as marginalia or composed using digital technology, the social life of this book will be recursively authored by students, scholars, designers, and educators who may share both this book and their annotation in conversation with one another, enabling collaborative forms of reading, writing, and meaning-making (Liu, 2006; Reid, 2019).

When annotated, the text of this book will become a context for discussion, analysis, and shared inquiry. Should multimodal notes be added to a digital or online version of this book, this annotation may encourage social participation and discourse. Social annotation is a genre of learning technology that enables information sharing, peer interaction, collaboration, and the production of new knowledge (Novak, Razzouk, \& Johnson, 2012). Moreover, should interactive notes be directly tethered to an online version of this text, social annotation will create the conditions for this book and its chapters to function as an anchored environment (Gao, Zhang, \& Franklin, 2013) whereby learners can collectively develop familiarity with new ideas and construct new knowledge (e.g., Chen, 2019). Annotation has long been associated with education (Adler, 1940; Brown \& Smiley, 1978; Wolfe, 2002). Today, advances in social annotation technology and pedagogical experimentation among anchored discursive environments have inspired new forms of collaborative reading, sense-making, and open learning (Kalir \& Garcia, 2019; Mirra, 2018; Sprouse, 2018).

Collaborative activity mediated by social annotation-and whether anchored to this book, or to texts like ebooks, PDFs, blog posts, and open textbooks-will generate digital information that may be gathered, analyzed, reported, and interpreted as discourse data (e.g., Sun \& Gao, 2017). Notably, educational researchers interested in 
online discussion and collaborative learning are developing new designs and methods that have proven useful in establishing connections among social annotation, discourse data, and learning analytics. For example, Chen's (2019) study of "networked discourse" examined social annotation data to describe the ways in which "students were engaged in sensemaking, sensegiving, problem-solving, artifact creation, and deepening discussion around knowledge artifacts" (p. 199). Plevinski and colleagues' (2017) investigation of undergraduate students' social annotation combined descriptive statistics with content analysis and found that elaboration and interpretation were common knowledge construction activities. Studies of educators' social annotation have utilized methods like social network analysis (Kalir \& Perez, 2019) to detail discourse patterns in openly-networked and interest-driven professional learning. When texts like this book anchor social annotation, it is feasible for researchers to derive insight about group activity, meaning-making, and collaboration through the analysis of discourse data.

The annotation of this book is, of course, a probable though hypothetical scenario. Nevertheless, this scenario is pertinent to the relationship between learning analytics and OFDL for it raises a number of broad questions. First, how can advances in open technology shape the ways in which people read, write, and make meaning together through their engagement with shared texts? Second, might open discourse data, interpreted and made actionable as social learning analytics (Buckingham Shum \& Ferguson, 2012), help to describe and encourage collaborative activity? Third, how can the public reporting of social learning analytics -in partnership with learners and other stakeholders-encourage sustained collaboration? Fourth, how might data systems reporting social learning analytics strengthen OFDL infrastructures?

These questions are raised not to guide a novel empirical study but are shared as generative queries that have influenced the design and research of an interdisciplinary team working at the intersection of social annotation, learning analytics, and OFDL. Since 2017, our team-a group with expertise in the learning sciences, data sciences, technology design, and teacher education-has collaborated with multiple stakeholders to iterate a public dashboard that visualizes openly accessible discourse data generated via social annotation as social learning analytics (e.g., Kalir, 2020). The creation of any particular learning analytics tool is not without concern, and there is a need to critically question the purpose and development of such technologies (Perrotta \& Williamson, 2018; Selwyn, 2019), advance designs grounded in learning theory (Matcha, Uzir, Gašević, \& Pardo, 2019), and describe "complex narratives" because "we [learning analytics scholars] are not aware of intimate, first-hand accounts of the building experience of educational data infrastructures" (Johanes \& Thille, 2019, p. 2970).

In response, this chapter recounts one approach to ethically co-designing a public dashboard that reports social learning analytics and encourages learners' collaborative annotation across open texts and contexts. As a contribution to "designerly work" in the learning sciences (Svihla \& Reeve, 2016), this chapter is a reflective, firsthand account organized around three related objectives:

1. Naming the theoretical stances toward open and social learning that informed design and research; 
2. Describing key decisions and trade-offs pertinent to four iterations of a social learning analytics dashboard; and

3. Considering epistemological, technological, and infrastructural implications for the development and use of social learning analytics in OFDL.

\section{Open and Social: Activity, Annotation, and Analytics}

The design and research efforts detailed in this chapter reflect insight from learning theory about the relationships among open and social activity, annotation, and analytics.

Amidst myriad interpretations of what counts as "open" in education and related professional and political contexts (Conrad \& Prinsloo, 2020; Pomerantz \& Peek, 2016), OFDL may be theoretically grounded in a broader conception of learning as participation in social activity (George, 1995; Lave \& Wenger, 1991). People learn through participation in authentic and cultural practices across a range of everyday and academic settings (National Academies of Sciences, Engineering, and Medicine, 2018). Learning processes, like collaboration and meaning-making, may be understood as group-level processes (Stahl, 2017) rather than as an indicator of individual accomplishment. Moreover, because learning is situated in both everyday and designed contexts, groups rely upon their use of tools, shared resources, and distributed cognition to engage in joint activity (e.g., Slakmon \& Schwarz, 2017). From this perspective, OFDL is conceived of as access to and participation in authentic social activity among and across networks comprised of people, shared technologies, and material and ideational resources that enable negotiation, meaning-making, and knowledge construction (e.g., Bali \& Caines, 2018; West-Puckett, Smith, Cantrill, \& Zamora, 2018).

As noted, social annotation is one example of open and collaborative activity that demonstrates group-level learning both within and beyond the boundaries of formal educational institutions (e.g., Siemens, Arbuckle, Seatter, El Khatib, \& El Hajj, 2017). In one respect, the open and social qualities of annotation resemble how scholars have described open educational practices as accessible, networked, transparent, and relevant to collaborative academic activities like teaching and publication (Cronin \& MacLaren, 2018). Alternatively, the open and social qualities of annotation echo critical literacy practices (Ávila \& Pandya, 2013) including, specifically, the expansive possibilities of writing: "Writing serves many purposes: to exchange ideas, explain positions, critique perspectives, question values, establish points of view, and reflect on beliefs that may contradict other people's beliefs" (Kinloch, 2010, p. 44). Yet again, it is also useful to perceive the open and social attributes of annotation as reflecting connected learning (West-Puckett et al., 2018) whereby a group that adds notes to a common text evidences affinity among networked opportunities, supportive relationships, and shared interests (e.g., Kalir \& Garcia, 2019). Together, these perspectives contribute to a more robust theoretical understanding of how annotation enables open and social learning.

Tracing linkages from activity to annotation to analytics, it is important to note that the frequent association of learning analytics with students and schooling has elicited skepticism and critique (e.g., Broughan \& Prinsloo, 2019; Rubel \& Jones, 2016). Nonetheless, acknowledging open and collaborative activity beyond institutional 
boundaries can motivate an appreciation for the promise of social learning analytics (SLA). Buckingham Shum and Ferguson (2012) define SLA as a "subset" of learning analytics relevant to participatory online cultures and resonant with the previously described socio-cultural perspectives on learning. Specifically, SLA are intended to help describe and make actionable group processes like collaboration: "The focus of social learning analytics is on processes in which learners are not solitary, and are not necessarily doing work to be marked, but are engaged in social activity, either interacting directly with others... or using platforms in which their activity traces will be experienced by others" (p. 5). Research by Chen and colleagues (2018), for example, detailed opportunities and challenges when implementing a SLA toolkit intended to foster undergraduate students' social interaction and conceptual engagement. Outside a formal course context, Gruzd and colleagues (2016) have demonstrated methods for collecting, analyzing, and visualizing social forms of learning analytics in order to "open up possibilities for understanding designed and emergent online learning practices as supported through social media" (p. 65). A value of SLA is focus on the creation of tools and methods to make both accessible and actionable group-level activity that occur in participatory online cultures, whether associated with social media or social annotation, in order to encourage ongoing joint activity.

Together, a complementary stance toward open and social activity, annotation, and analytics suggests the addition of notes to a text-like this book, and whether in print or digital form-can be understood as authentic activity relevant to group-level discourse, interpretation, negotiation of meaning, and knowledge construction. The open and social annotation of a digital text is also reflective of group-level educational and literacy practices that are collaborative, critical, and connected. Furthermore, participatory patterns and discourse data associated with a digital text's open and social annotation can be reported as SLA to better understand group processes, make accessible activity patterns, and encourage learners' ongoing interaction, meaningmaking, and the production of new knowledge.

\section{Reporting Crowd Annotation, Encouraging Discourse Layers}

The remainder of this chapter synthesizes commitments from learning theory to provide a first-hand account of the development of a public SLA dashboard that reports grouplevel social annotation and encourages open learners' discourse and collaboration. Social annotation does enable group activity in formal course contexts that may exhibit open qualities (e.g., Chen, 2019). However, our design and research efforts have been motivated by -and remain responsive to-a public, openly-networked, and interestdriven learning initiative facilitated online and made possible because of contributions from educational stakeholders. Rather than retrace a linear narrative, this chapter highlights key opportunities, complexities, and trade-offs that characterize how we sought to productively support intersections among social annotation, open learning, and learning analytics.

\section{Design Context}


First-hand accounts can be valuable because they showcase designers navigating technical decisions while also describing how "builders are aware of and engage with the epistemological, methodological and ethical aspects of infrastructures" (Johanes \& Thille, 2019, p. 2960). This account draws from and combines design documentation, stakeholder feedback cycles during prototyping, focus groups with active communities, ongoing issue and feature tracking, and public responses elicited from blog posts and social media.

Since 2016, the Marginal Syllabus has sparked and sustained openly accessible conversation about educational equity through collaborative technologies and partnerships (Kalir, 2020). Project partners-including the National Writing Project, the National Council of Teachers of English, and the web annotation organization Hypothesis-have created a professional learning initiative that invites K-12 and postsecondary educators to: a) read and discuss academic scholarship featuring perspectives that are marginal to dominant education norms; b) engage publicly with one another among marginal digital spaces as mediated by social annotation; and c) document professionally-relevant meaning and knowledge using an open-source social annotation tool (Hypothesis) that is marginal to commercial educational technology. Figure 1 is a representative scholarly text functioning as a discursive context, with Hypothesis anchoring educators' social annotation during Marginal Syllabus activity.

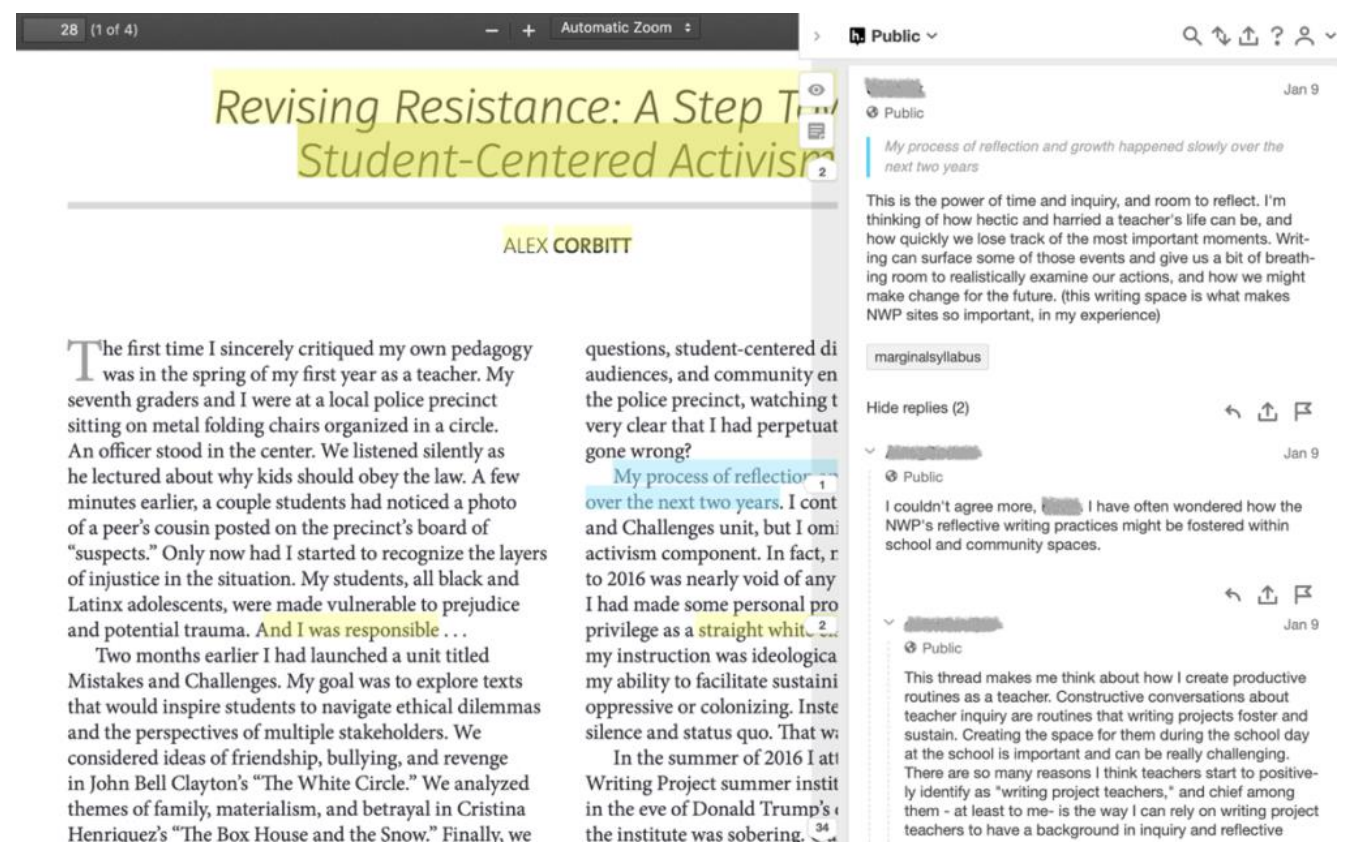

Figure 1: Open access text annotated using Hypothesis social annotation tool

Akin to an online book club or study group, the Marginal Syllabus "promote[s] transformative learning as dialogue" (Bali \& Caines, 2018, p. 14) and demonstrates what Greenhow and colleagues (2019) describe as the "social scholarship of teaching," or an opportunity for educators share to their knowledge and produce new meaning about teaching through social and collaborative media practices. The Marginal Syllabus' distinctive approach to public engagement with open access scholarship for the 
purposes of collaborative learning has been aptly captured by one partner author whose research was annotated in 2017:

Through this initiative... I was given the opportunity to imagine a different paradigm for conducting, consuming, and responding to research-one in which study findings become the start rather than the end of dialogue and in which diverse forms of expertise extend, refute, and re-mix the knowledge production process for the common purpose of making education more equitable and culturally sustaining. (Mirra, 2018, p. 30)

To date, the Marginal Syllabus has facilitated over four dozen public conversations which have elicited contributions from over 600 educators who have authored nearly 7,000 open annotations (these descriptive statistics do not include participation and annotation counts associated with closed groups; anecdotal evidence suggests Marginal Syllabus texts are regularly annotated privately in the context of teacher education courses). As a result, public activity from educators' social annotation authored during Marginal Syllabus activity comprise a sizable corpus of growing discourse data.

During the 2017-18 academic year, a need emerged to develop additional context-sensitive technical and social supports that could encourage open and ongoing participation in the Marginal Syllabus' annotation conversations. Further, shared interest in open (educational) principles and technologies (e.g., Pomerantz \& Peek, 2016), as well as methods to report and visualize emergent social learning (e.g., Gruzd et al., 2016), motivated the design of a learning analytics tool responsive to both the open scholarship annotated during Marginal Syllabus activity and also any document annotated using Hypothesis anywhere on the web. Similarly, we endeavored to design a tool that could easily be incorporated into open learning environments, like the Marginal Syllabus, as well as more formal course contexts given the use of social annotation in school. Stakeholder feedback indicated that it would be beneficial to design a tool that simultaneously encouraged educators' participation in their own open learning while also modeling how discourse data could be visualized and made actionable should these same educators incorporate social annotation activities into their courses and curricula.

\section{Dashboard Traits and Design Trade-offs}

The first public iteration of a tool for Capturing and Reporting Open Web Data for Learning Analytics, Annotation, and Education Researchers (CROWDLAAERS; pronounced "crowd layers"; crowdlaaers.org) was released in early 2018.

CROWDLAAERS is a SLA dashboard that visualizes group-level (or "crowd") activity with the intention of encouraging additional social annotation (or "layers"). At its core, the technical capability of CROWDLAAERS to capture and report open web data is made possible by querying the Hypothesis API; as a standards-based and interoperable technology, Hypothesis makes available open data and metadata associated with social 
annotation. Figure 2 is an image of the current CROWDLAAERS dashboard highlighting the interactive threads visualization (similar data tables for annotations, participants, documents, days, and tags are collapsed or not pictured); and Figure 3 is an image of closed-group activity across multiple documents.

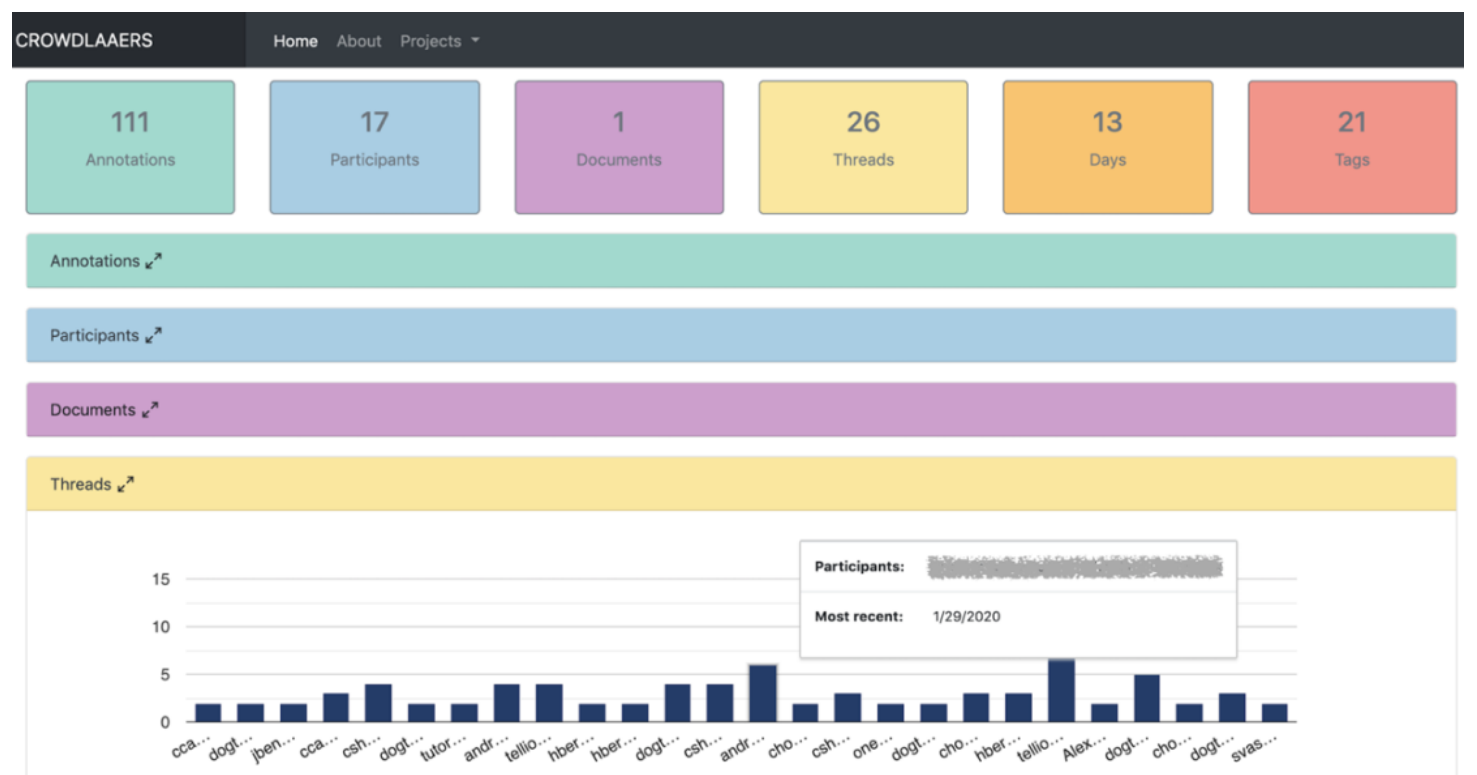

Figure 2: CROWDLAAERS visualizing open and social annotation threads

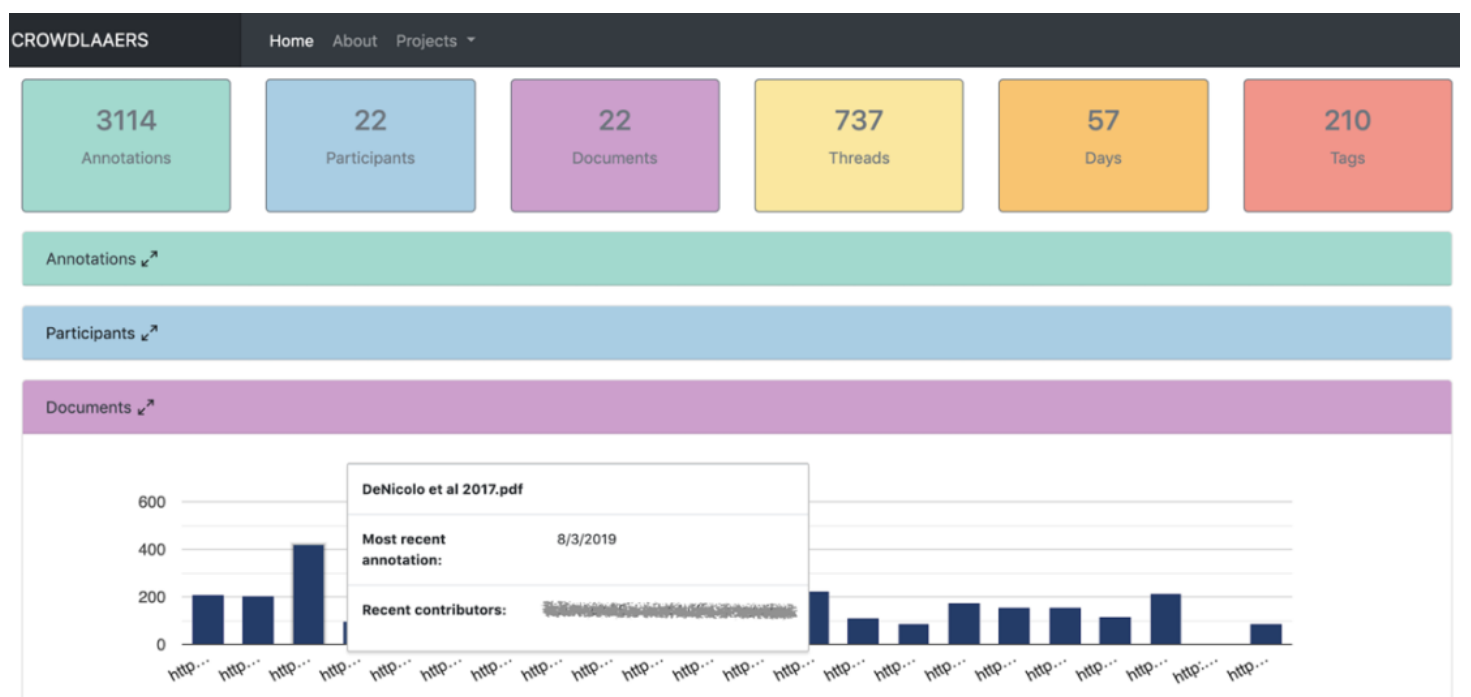

Figure 3: CROWDLAAERS visualizing closed-group social annotation across multiple documents

Each of four CROWDLAAERS iterations has sought to more effectively summarize, visualize, and present elements of open data and metadata as SLA relevant to understanding group annotation and encouraging subsequent discourse. Prior to the second iteration, for example, stakeholder recommendations informed two 
decisions: first, to feature an interactive table of all annotation content associated with a given document; and second, to access via this table each annotation in context, thereby providing a direct connection back to the annotated text and lowering barriers of reentry for ongoing social activity (this latter feature is possible because each Hypothesis annotation is a distinct URL, provisioning a linkage between dashboard and document). Feedback from project stakeholders motivated a third iteration focused on searching and sharing that broadened the dashboard's public accessibility and relevance, consequently shifting the focus from texts annotated during Marginal Syllabus activity to any text annotated with Hypothesis. By visualizing open and social annotation anywhere on the web, CROWDLAAERS was adopted by both open learning projects as well as K-12 and post-secondary educators using Hypothesis in their courses. Feature requests from this broader user community prompted a fourth iteration and two improvements: access to closed-group activity given that Hypothesis social annotation in course contexts is frequently private; and multi-document visualization as both open learning and formal course activities often include learners reading and collaboratively annotating multiple texts.

While iterating CROWDLAAERS, dashboard improvements have not dismissed design tensions associated with learning analytics and ethics (Slade \& Prinsloo, 2013). As noted, CROWDLAAERS gathers open annotation data by querying the Hypothesis API. However, CROWDLAAERS was purposefully designed as a light-weight and server-less tool that does not store any Hypothesis data. By not storing annotation data, we have intentionally limited the dashboard's technical capability to complete more advanced analyses of collaborative activity and visualize additional forms of SLA (i.e. social networks and how those networks change over time). Our decision is intended to respect people's ownership of their annotation data yet also results in a dashboard that only reports real-time SLA. If someone makes their public Hypothesis annotations private or deletes their annotations altogether, then CROWDLAAERS cannot capture or report that data because the data have never been stored anywhere. This trade-off favors people's data rights over the dashboard's potential analytic insights.

Another convergence of dashboard traits and design trade-offs emerged throughout the 2018-19 academic year. During this period in time, CROWDLAAERS was adopted by multiple open learning projects beyond the Marginal Syllabus, including: Equity Unbound, an open curriculum guiding participants to read about and discuss topics like empathy, privacy, and digital wellbeing; a public and collaborative annotation of Augmenting Human Intellect: A Conceptual Framework (Engelbart, 1962) in partnership with the Doug Engelbart Institute; and the Right to Learn Dignity Lab (R2L), a university-based group studying case law to understand how concepts of dignity and equality are fundamental to the right of personhood. In addition to supporting CROWDLAAERS use by these projects, faculty at five different North American institutions were also assisted as they leveraged the dashboard and piloted a multidocument "course collections" prototype to gain insight into their students' annotation patterns, reading comprehension, and engagement with discipline-specific texts.

The R2L use case was a notable collaboration that helped advance how CROWDLAAERS supported group-level annotation across multiple documents. At the time, R2L was studying educational dignity in four landmark American court cases that required members of the group-often working asynchronously and across continents- 
to read together and collaboratively annotate the case's complaints, amicus briefs, oral arguments, and final opinions. This corpus of 52 documents totaled over 2,000 pages; accordingly, "Hypothesis was our tool of choice because of its capacity to function as a digital historian of our thinking" (University of Colorado Denver, 2020).

CROWDLAAERS enabled R2L to pilot multi-document workflows that would be refined into the current feature allowing access to SLA from closed-group activity across all the texts annotated by a group (Figure 3).

Throughout this intensive stage of partnership and iteration, design decisions became responsive-almost exclusively - to the requests of stakeholders and active communities. For example, two of CROWDLAAERS' interactive tables (documents and threads) came to include a hover-over feature that displays a summary of recent participants and the date of the latest annotation. This change better informed users about what specific SLA to select and examine at a more granular level. All six interactive tables were also designed so that each could be collapsed, expanded, and filtered to minimize information overload and aid focus on a particular set of SLA. An in thread feature was added to more easily filter the annotations table in order to highlight a single set of interactions. These features were not the result of creative technical innovation but, more importantly, honored emergent stakeholder needs. Incorporating these changes into CROWDLAAERS underscored how stakeholders' knowledge about tool use in actual OFDL environments was as important a form of expertise as designers' technical know-how. Creating new dashboard attributes accompanied a shift in role and responsibility-from sharing a public-facing tool to facilitating co-design processes supportive of specific educational communities. As another indicator of commitments to open learning processes and groups, the CROWDLAAERS code was shared on GitHub making the dashboard open-source software and a contribution to the open web.

\section{Conclusion}

When this book is read and annotated by a group to aid collaborative meaning-making and learning, it is feasible for certain types of learning analytics methods and tools to productively enable open and social activity. The creation of CROWDLAAERS reflects intertwined epistemological and technical commitments relevant to future design and research should readers - as annotators of this book and other texts-work at the convergence of learning analytics and open learning. Such future efforts can draw upon and extend three key findings.

First, as one response to opportunities identified in the literature (e.g., Johanes \& Thille, 2019), this chapter has modeled a theoretically-grounded, first-hand account of a learning analytics dashboard developed for use in OFDL contexts. Design decisions underscore the importance of creating technology that focuses on and makes actionable SLA for ongoing group activity in context (e.g., Chen et al., 2018), rather than analytics tools that entrench tracking, measurement, and evaluation of individual performance irrespective of group interaction or sociopolitical concern (Perrotta \& Williamson, 2016; Selwyn, 2019). Furthermore, and in light of the connectedness of many open learning initiatives, this chapter has also made an argument regarding the benefits of co-designing tools-like a public SLA dashboard—alongside stakeholders 
whose partnership informs ethical stances, guides technical decisions, and motivates iterative improvements that meet actual learning needs.

Second, advances in learning analytics need not be constrained by or exclusively concerned with conceptions of knowing that privilege schooling, individual students, or solitary cognition. On the contrary, receptiveness to open learning opportunities should motivate tool development and research agendas that honor how knowledge is socially situated and openly-networked, how discourse and activity emerge from and occur because of participatory group processes, and how analytic insight should reflect knowledge construction in context (Buckingham Shum \& Ferguson, 2012; Gruzd et al., 2016). To usefully document and make actionable insight about the social production of knowledge also means partnering to produce tools which reify activity traces, discourse patterns, and group-level processes-such as those mediated by open and social annotation - that are comprehensible to and in service of stakeholder groups.

Third, this chapter suggests it may be productive to build open technology that both supports open learning while also strengthening the infrastructure of the open web. Annotation is an infrastructural element of the open web (Whaley, 2017). The Hypothesis organization helped galvanize the creation of a standardized and interoperable annotation data model while simultaneously making publicly available a tool that enables social annotation anywhere online. As described, Hypothesis annotation has been embraced by learners, educators, and researchers across a range of OFDL environments (Chen, 2019; Sprouse, 2018). In response, an open-source SLA dashboard can take advantage of these emerging socio-technical arrangements and activities. Future SLA tools aligned with this annotation standard can iterate and improve the CROWDLAAERS dashboard, while also extending the ways in which open annotation data functions as an accessible and useful form of learning analytics. This first-hand account is one small but concrete contribution to promising efforts intended to encourage learners' sustained collaboration across open texts and contexts while mutually architecting publicly available and reconfigurable open learning infrastructure. 


\section{References}

Adler, M. (1940). How to mark a book. The Saturday Review, 11-12.

Ávila, J., \& Pandya, J. (Eds.). (2013). Critical digital literacies as social practice: Intersections and challenges. New York, NY: Peter Lang.

Bali, M., \& Caines, A. (2018). A call for promoting ownership, equity, and agency in faculty development via connected learning. International Journal of Educational Technology in Higher Education, 15(46).

Broughan, C., \& Prinsloo, P. (2019). (Re)centring students in learning analytics: in conversation with Paulo Freire. Assessment \& Evaluation in Higher Education, 112.

Brown, J. S., \& Duguid, P. (1996). The social life of documents. First Monday, 1(1). Retrieved from https://firstmonday.org/article/view/466/387

Brown, A., \& Smiley, S. (1978). The development of strategies for studying texts. Child development, 1076-1088.

Buckingham Shum, S., \& Ferguson, R. (2012). Social learning analytics. Journal of Educational Technology \& Society, 15(3), 3-26.

Chen, B. (2019). Designing for networked collaborative discourse: An UnLMS approach. TechTrends, 63(2), 194-201.

Chen, B., Chang, Y. H., Ouyang, F., \& Zhou, W. (2018). Fostering student engagement in online discussion through social learning analytics. The Internet and Higher Education, 37, 21-30.

Conrad, D., \& Prinsloo, P. (Eds.). (2020). Open(ing) education: Theory and practice. Boston, MA: Brill USA.

Cronin, C., \& MacLaren, I. (2018). Conceptualising OEP: A review of theoretical and empirical literature in Open Educational Practices. Open praxis, 10(2), 127-143.

Engelbart, D. (1962). Augmenting human intellect: A conceptual framework. Menlo Park, CA: Stanford Research Institute.

Fajkovic, M., \& Björneborn, L. (2014). Marginalia as message: Affordances for readerto-reader communication. Journal of Documentation, 70(5), 902-926.

Gao, F., Zhang, T., \& Franklin, T. (2013). Designing asynchronous online discussion environments: Recent progress and possible future directions. British Journal of Educational Technology, 44(3), 469-483.

George, R. (1995). Open and distance education as social practice. Distance Education, 16(1), 24-42.

Greenhow, C., Gleason, B., \& Staudt Willet, K. B. (2019). Social scholarship revisited: Changing scholarly practices in the age of social media. British Journal of Educational Technology, 50(3), 987-1004.

Gruzd, A., Paulin, D., \& Haythornthwaite, C. (2016). Analyzing social media and learning through content and social network analysis: A faceted methodological approach. Journal of Learning Analytics, 3(3), 46-71.

Johanes, P., \& Thille, C. (2019). The heart of educational data infrastructures = Conscious humanity and scientific responsibility, not infinite data and limitless experimentation. British Journal of Educational Technology, 50(6), 2959-2973.

Kalir, J. (2020). Social annotation enabling collaboration for open learning. Distance Education, 41(2). 
Kalir, J., \& Garcia, A. (2019). Civic writing on digital walls. Journal of Literacy Research, $51(4), 420-443$.

Kalir, J., \& Perez, F. (2019). The Marginal Syllabus: Educator learning and web annotation across sociopolitical texts and contexts. In A. Reid (Ed.), Marginalia in modern learning contexts (pp. 17-58). Hershey, PA: IGI Global.

Kinloch, V. (2010). Harlem on our minds: Place, race, and the literacies of urban youth. New York, NY: Teachers College Press.

Lave, J., \& Wenger, E. (1991). Situated learning: Legitimate peripheral participation. Cambridge, UK: Cambridge University Press.

Liu, K. (2006). Annotation as an index to critical writing. Urban Education, 41(2), 192207.

Marshall, C.C. (1997). Annotation: From paper books to the digital library. In Proceedings of the Second ACM International Conference on Digital Libraries (pp. 131-140).

Matcha, W., Gasevic, D., \& Pardo, A. (2019). A systematic review of empirical studies on learning analytics dashboards: A self-regulated learning perspective. IEEE Transactions on Learning Technologies.

Mirra, N. (2018). Pursuing a commitment to public scholarship through the practice of annotation. The Assembly, 1. Retrieved from https://www.colorado.edu/journal/assembly/2018/12/12/pursuing-commitmentpublic-scholarship-through-practice-annotation

National Academies of Sciences, Engineering, and Medicine. (2018). How People Learn II: Learners, Contexts, and Cultures. Washington, DC: The National Academies Press.

Novak, E., Razzouk, R., \& Johnson, T. E. (2012). The educational use of social annotation tools in higher education: A literature review. Internet and Higher Education, 15(1), 39-49.

Perrotta, C., \& Williamson, B. (2018). The social life of learning analytics: Cluster analysis and the 'performance' of algorithmic education. Learning, Media and Technology, 43(1), 3-16.

Plevinski, J., Weible, J. \& Deschryver, M. (2017). Anchored annotations to support collaborative knowledge construction introduction. In Making a difference: Prioritizing equity and access in CSCL, 12th International Conference on Computer Supported Collaborative Learning (CSCL) 2017 (pp. 111-118).

Pomerantz, J., \& Peek, R. (2016). Fifty shades of open. First Monday, 21(5). Retrieved from https://firstmonday.org/ojs/index.php/fm/article/view/6360/5460

Reid, A. (Ed.). (2019). Marginalia in modern learning contexts. Hershey, PA: IGI Global.

Rubel, A., \& Jones, K. M. (2016). Student privacy in learning analytics: An information ethics perspective. The Information Society, 32(2), 143-159.

Selwyn, N. (2019). What's the problem with learning analytics?. Journal of Learning Analytics, 6(3), 11-19.

Siemens, R., Arbuckle, A., Seatter, L., El Khatib, R. \& El Hajj, T. (2017). The value of plurality in "The Network with a Thousand Entrances," International Journal of Humanities and Arts Computing, 11(2), 153-173.

Slade, S., \& Prinsloo, P. (2013). Learning analytics: Ethical issues and dilemmas. American Behavioral Scientist, 57(10), 1509-1528. 
Slakmon, B., \& Schwarz, B. B. (2017). "Wherever you go, you will be a polis": Spatial practices and political education in computer-supported collaborative learning discussions. Journal of the Learning Sciences, 26(2), 184-225.

Sprouse, M. (2018). Social annotation and layered readings in composition. 2018 Computers \& Writing Conference, 39-52.

Stahl, G. (2017). Group practices: A new way of viewing CSCL. International Journal of Computer-Supported Collaborative Learning, 12(1), 113-126.

Sun, Y., \& Gao, F. (2017). Comparing the use of a social annotation tool and a threaded discussion forum to support online discussions. Internet and Higher Education, 32, 72-79.

Svihla, V., \& Reeve, R. (Eds.). (2016). Design as scholarship: Case studies from the learning sciences. New York, NY: Routledge.

University of Colorado Denver. (2020, March 6). Manuel Espinoza-Chancellor's Distinguished Faculty Lecture [video]. Youtube. https://youtu.be/kEtjCZoTPps

West-Puckett, S., Smith, A., Cantrill, C., \& Zamora, M. (2018). The Fallacies of Open: Participatory Design, Infrastructuring, and the Pursuit of Radical Possibility. Contemporary Issues in Technology and Teacher Education, 18(2), 203-232.

Whaley, D. (2017). Annotation is a now a web standard. Retrieved from https://Hypothes.is/blog/annotation-is-now-a-web-standard/

Wolfe, J. (2002). Marginal pedagogy: How annotated texts affect a writing-from-sources task. Written Communication, 19(2), 297-333.

Zhang, J., Burgos, D., \& Dawson, S. (2019). Advancing open, flexible and distance learning through learning analytics. Distance Education, 40(3), 303-308. 